\title{
Feeding and Burrowing Behaviors of a Deposit-feeding Capitelid Polychaete, Capitella sp. I
}

\author{
Hiroaki Tsutsumi , Akiko Taniguchi and Noriko Sakamoto \\ Faculty of Environmental and Symbiotic Sciences, Prefectural University of Kumamoto, \\ Tsukide 3-1-100, Kumamoto 862-8502, Japan
}

\begin{abstract}
A capitelid small polychaete, Capitella sp. I, is a head-side down deposit feeder, which often occurs densely in organically enriched sediment. In this study, we observed burrowing and feeding behaviors of this species, and conducted laboratory experiments, examining the impact of reworking activities of the worms on the physics and chemistry of the organically enriched sediment. The laboratory experiments revealed that the worms fed not only the subsurface sediment but also the surface sediment selectively. The burrowing and feeding activities of the worms in the sediment were activated by the addition of organic matter on the sediment surface. The reworking activities of the worms include burrowing into the sediment, spouting the subsurface layers of the sediment onto the sediment surface, feeding on the sediment and excreting the sediment as fecal pellets on the sediment surface. The amount of spouted sediment on the sediment surface caused by burrowing activities was approximately 2.6 times larger than the amount of sediment reworked by excretion of fecal pellets. We estimated that approximately $162 \mathrm{gDW}$ per day of the sediment could be reworked by 30,000 adult worms with $1 \mathrm{~mm}$ of maximum width of thoracic segments. This reworking rate indicated that one square meter of the subsurface sediment with $2 \mathrm{~cm}$ in thickness, $75 \%$ of water content and 1.7 of specific gravity should be reworked within 52.5 days.
\end{abstract}

Key words: burrowing, Capitella, feeding, organic enrichment, oxidation, reworking

\section{INTRODUCTION}

Capitelid polychaetes are typical head-side down burrowers in the muddy sediment. They usually swallow the sediment by everting a papillose sac-like pharynx in the burrows, ingest the organic matter of the sediment, and excrete as fecal pellets on the sediment surface. Therefore, they are classified as burrowing, mortile, and deposit feeders (cf. Jumars \& Fauchald 1977; Fauchald \& Jumars 1979; Forbes \& Lopez 1990).

All capitelids are considered non-selective in their feeding. The list of gut contents, however, nearly always includes algal fragments, suggesting the some selection is probable (Fauchald \& Jumars 1979). Among these capitellid polychaetes, Capitella sp. I (Grassle \& Grassle 1976) and several closely related sibling species are threadlike small species and common members of the benthic communities in organically enriched sediment in coastal areas throughout the world (Pearson \& Rosenberg

Received June 15, 2005: Accepted August 30, 2005
1976, 1978; Reish 1971, 1979; Diaz \& Pearson 1995). They feed the organically enriched sediment and often exhibit explosive population growth, and establish dense patches in organically enriched sediment within several months (Grassle \& Grassle 1974; Tsutsumi \& Kikuchi 1983; Tsutsumi 1987, 1990; Tsutsumi et al. 1991).

Reish (1974) showed that Capitella colonies could be maintained on a diet of a green alga, Enteromorpha sp., or alfalfa powder. Tsutsumi et al. (1990) demonstrated that Capitella sp. I occurring in organically enriched sediment physiologically required the organically enriched sediment for its normal growth. It is to be expected that Capitella sp. I feed on the organically enriched sediment very selectively, and its burrowing and feeding activities should have a great impact on the physical and chemical characteristics of the sediment. Tsutsumi \& Montani (1993) and Chareonpanichi et al. (1993, 1994) showed experimentally in the laboratory that the presence of dense patches of Capitella sp. I markedly promoted oxidation of reduced substances such as AVS (Acid Volatile Sulfides) and decomposition of the organic matter in the organically enriched sediment. Tsutsumi et al. (2002) also showed the same impact on the chemistry 
of the sediment in the process of fast population growth of Capitella sp. I in outside pools. Tsutsumi et al. (in press) developed a new technique of bioremediation of organically enriched sediment, utilizing these characteristics of Capitella sp. I. They artificially mass-cultured the Capitella colonies, scattered them on the organically enriched sediment just below the net pens for fish farming, and realized explosive population growth of this species and marked enhancement of decomposition of the organic matter and oxidation of reduced sulfides in the sediment.

In this study, we observed the burrowing and feeding behaviors of Capitella sp. I rearing in the organically enriched sediment in the laboratory conditions, and examined where the worms feed the sediment, how they exploit the food resources in the sediment, and consequently how these behaviors rework the sediment and modify the physical structure and chemical characteristics of the sediment. We discuss the ecological significance of the burrowing and feeding behaviors of the worms in the organically enriched sediment.

\section{MATERIALS AND METHODS}

Sediment and sea water used for the experiments were collected from Dokai Bay, Kitakyushu and Tomioka Bay, Amakusa, Kumamoto Prefecture, Japan, respectively. Prior to use for the experiments, the mud was frozen at $-20^{\circ} \mathrm{C}$ to kill benthic animals therein and thawed, and the sea water was filtered with a glass fiber filter (GC 50) and a membrane filter (Cellulose Nitrate $0.45 \mu \mathrm{m}$ ). Capitella sp. I was collected from Tomoe Cove, Tomioka, Amakusa, Kumamoto prefecture, Japan. We established the laboratory colonies of Capitella sp. I, and used them for the experiments.

In this study, we conducted the following four different experiments using the containers in the laboratory.

\section{Experiment 1: Observation of burrowing and feeding behaviors}

We prepared containers made of acrylic resin for the experiments $(180 \times 85 \times 160 \mathrm{~mm})$ (Fig. 1). We put the sediment in the containers at $3 \mathrm{~cm}$ in depth and sea water at $5 \mathrm{~cm}$ in depth, and gently aerated the sea water with an air stone. On the sediment surface of the containers, we put a white-colored mixture with the natural sediment $(20 \%)$ and silicon dioxide $(80 \%)$ on the sediment surface at approximately $1 \mathrm{~mm}$ in depth. The water temperature was maintained at 19 to $22^{\circ} \mathrm{C}$. We released ten individu-

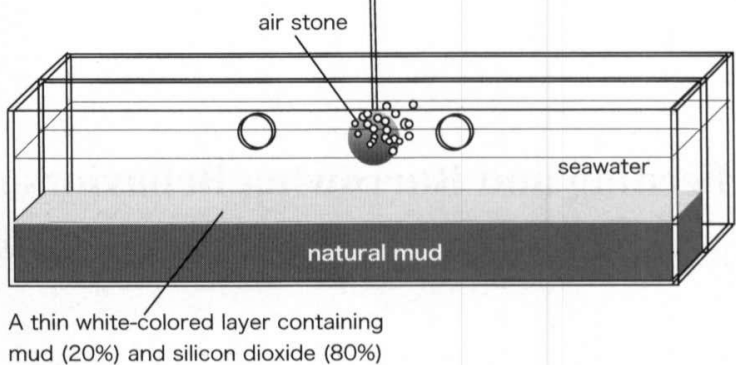

Fig. 1. Containers for the experiments. White-colored sediment including $80 \%$ of silicon dioxide was put at approximately $5 \mathrm{~mm}$ in depth on the sediment surface of the right container.

als of Capitella sp. I into the container, and observed the burrowing and feeding activities of the worms in the sediment.

\section{Experiment 2: Determination of reworking rate of the sediment}

We prepared five containers with the natural sediment, the white-colored mixture with the natural sediment $(20 \%)$ and silicon dioxide $(80 \%)$ on the sediment surface at approximately $1 \mathrm{~mm}$ in depth and sea water as the same manners with Experiment 1, and released a single individual of Capitella sp. I into each container. Every 24 hours, we collected the fecal pellets which were arranged like a tube and dark gray-colored sediment spouted from the subsurface layers on the white-colored surface sediment with a pipet, and determined how much the subsurface layer of the sediment was reworked per day by the burrowing and feeding activities. This experiment lasted at 19 to $22^{\circ} \mathrm{C}$ for 48 hours, and was duplicated.

The collected fecal pellets and spouted subsurface sediment were washed with distilled water three times to remove salt from them, dried with a drier at $50^{\circ} \mathrm{C}$, and weighed. At the end of the experiment, we collected the worm from each container, fixed it with $10 \%$ formalin solution, and measured the body size of the specimen (maximum width of thoracic segments, cf. Tsutsumi \& Kikuchi 1984) with a microscope image analyzer. The stereoscopic microscope image of the specimen was projected on a monitor of the personal computer (Apple, Power Macintosh 7600) through a CCD camera (SONY, DXC-930) equipped with a stereoscopic microscope (Olympus, SZH), and the length of the image was measured with image analysis software (NIH Image Ver.1.60). 


\section{Experiment 3: Impact of feeding activities on the chemistry of the sediment}

To assess the impact of feeding activities of Capitella sp. I on the chemistry of the sediment, we prepared four containers with only the natural sediment at $3 \mathrm{~cm}$ in depth and sea water at $5 \mathrm{~cm}$ in depth, and released ten individuals of the worms into each container. Prior to the experiments, we kept the worms in petri dishes with only sea water to remove the fecal pellets from their gut for one day. This experiment lasted at 19 to $22^{\circ} \mathrm{C}$ for four days. At the start, two days later and four days later (the end of the experiment), we collected the samples of the surface sediment up to approximately $5 \mathrm{mmin}$ depth and the fecal pellets excreted thereon with a pipette in each container. After the sampling of the surface sediment and fecal pellets, we added $0.05 \mathrm{~g}$ of powdered dry pellets used for fish culture (Soft Extruder Pellet, Mercian) on the sediment surface as available organic matter for the worms in two containers (Containers 3A). We did not add any organic matter on the sediment in the remaining two containers (Containers 3B) throughout the period of the experiment.

The sediment and fecal pellets collected from each container were freeze-dried once, treated with $2 \mathrm{~N} \mathrm{HCl}$ to remove inorganic carbonate, and vacuum-dried. We then determined total organic carbon (TOC) and total nitrogen (TN) with an elemental analyzer (Fisons, NA-1500).

\section{Experiment 4: Selective feeding of the surface sedi- ment}

To clarify whether the Capitella sp. I was able to feed on the surface sediment selectively, we examined the changes of the feeding and burrowing behaviors by addition of organic matter on the sediment surface. We prepared 10 containers with the natural sediment, the whitecolored mixture with the natural sediment $(20 \%)$ and silicon dioxide $(80 \%)$ on the sediment surface at approximately $1 \mathrm{~mm}$ in depth and sea water in the same manners with Experiment 1. We kept 100 individuals of Capitella $\mathrm{sp}$. I in the petri dishes with only sea water to remove the fecal pellets from their gut for one day, and released ten individuals in each container.

We conducted the experiment for 6 days. In five containers (Containers 4A), we added $0.05 \mathrm{~g}$ of powdered dry pellets used for fish culture on the sediment surface as available organic matter for the worms after sampling the fecal pellets on the sediment surface every day from three days after the start of the experiment. In the remaining five containers (Containers 4B), we did not add any organic matter on the sediment surface in the containers throughout the period of the experiment.

From each container, we daily collected the fecal pellets and dark gray-colored sediment spouted from the subsurface layers on the white-colored surface sediment with a pipet, counted the number of the white-colored and dark gray-colored fecal pellets under a stereoscopic microscope, and weighed the fecal pellets and the spouted sediment.

\section{RESULTS}

\section{Experiment 1: Observation of burrowing and feeding behaviors}

The white-colored sediment put on the sediment surface in the container facilitated the observation of movement of the sediment caused by the worms (Fig. 2). The movement of the sediment was characterized as follows.

1. Burrowing into the sediment and spouting it on the sediment surface

Capitella sp. I burrowed its way through the sediment, while the dark gray-colored subsurface sediment spouted on the white-colored sediment surface (Fig. 2). For burrowing into the sediment, the worms need to remove it outside. Although the mechanisms by which the sediment spouted from the subsurface layers could not be clearly observed, the spouting of the sediment always occurred from the head side of the worms in the subsurface layer of the sediment toward the sediment surface ahead of them.

2. Feeding the sediment and excreting fecal pellets Capitella sp. I fed the sediment and excreted it as fecal pellets on the sediment surface, arranging them spirally. As shown in Fig. 2, the fecal pellets consisted of not only dark gray-colored sediment that derived from the subsurface sediment but also white-colored surface sediment that we put on the surface of the sediment in the container. The presence of the white-colored fecal pellets indicates that the worms were able to feed on the surface sediment, although they burrow the sediment.

\section{Experiment 2: Determination of reworking rate of the sediment}

The reworking activities of the sediment by Capitella sp. I include feeding the sediment and excreting it on the sediment surface as fecal pellets and spouting the sediment for burrowing their way on the sediment surface 


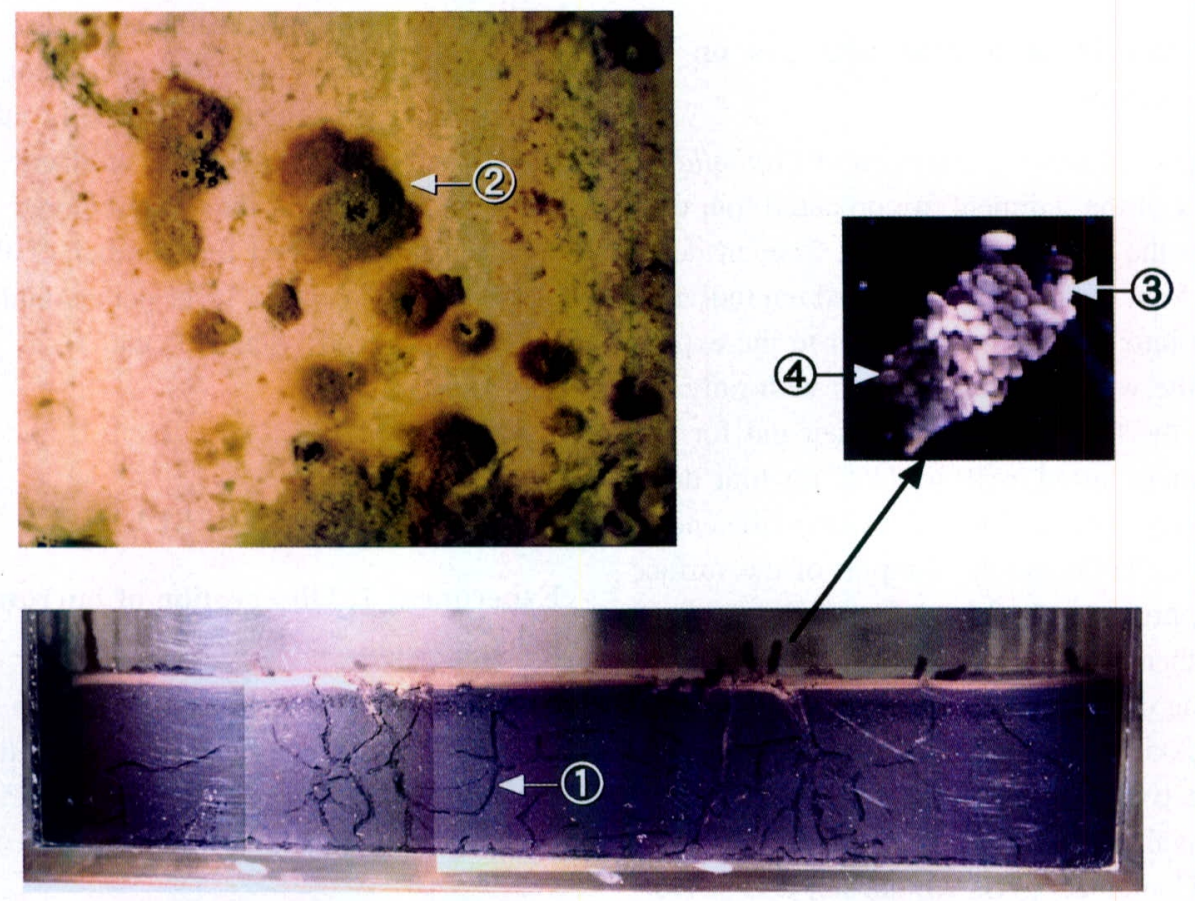

Fig. 2. Burrowing and feeding activities of Capitella sp. I. (1) Burrows; (2) Sediment spouted on the sediment surface from the subsurface layers; (3) White-colored fecal pellets consisting of a powder of silicon dioxide put on the sediment surface; (4) Dark gray-colored fecal pellets being made up of the subsurface layers of the sediment.

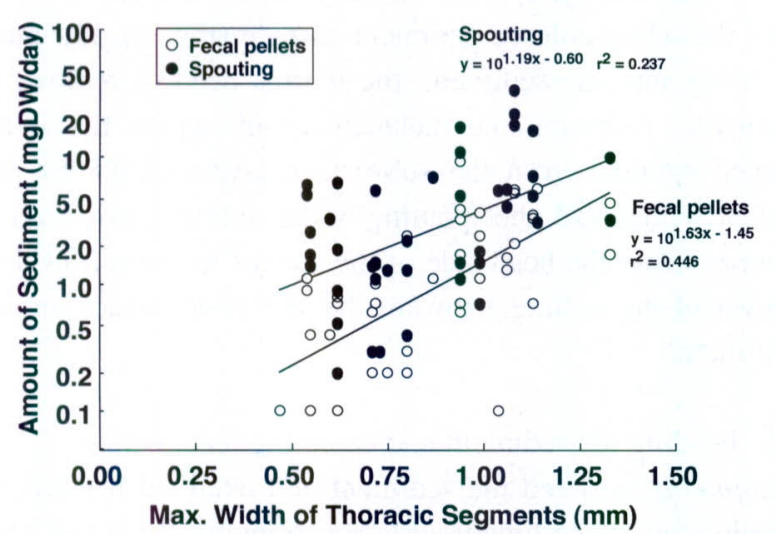

Fig. 3. The relationship between the body size of the worm and the amount of reworked sediment per day in Experiment 2.

(Fig. 2). In this experiment, we determined how much the sediment was reworked by Capitella sp. I per day. Fig. 3 shows the relationship between the body size of the worm and the amount of reworked sediment per day. The amount of reworked sediment caused by both feeding and spouting of the sediment by the worms tended to logarithmically increase with body sizes (fecal pellets: $y=10^{1.63 x-1.45}, r^{2}=0.446, p<0.01$; spouting the sediment: $\mathrm{y}=10^{1.19 x-0.60}, \mathrm{r}^{2}=0.237, p=0.01$, Perason's correlation coefficient). According to the relationship between the body size of the worm and the amount of reworked sediment, the worms with $1.0 \mathrm{~mm}$ of maximum width of the thoracic segments excret $1.5 \mathrm{mg}$ of fecal pellets and spout $3.9 \mathrm{mg}$ of the sediment on the sediment surface per day. In this case, the amount of spouted sediment on the sediment surface was 2.6 times larger than that of fecal pellets.

\section{Experiment 3: Impact of feeding activities on the} chemistry of the sediment

Fig. 4 and Fig. 5 show the changes of TOC and TN content of the surface sediment and the fecal pellets of the worms in Containers $3 \mathrm{~A}$ and $3 \mathrm{~B}$, respectively. At the start of the experiment, the contents of TOC and TN of the sediment were $74.1 \mathrm{mg} / \mathrm{g}$ and $2.7 \mathrm{mg} / \mathrm{g}$ in both containers. Two days later, the organic matter content of the fecal pellets of the worms in Containers $3 \mathrm{~A}$ and $3 \mathrm{~B}$ was $62.2 \mathrm{mg} / \mathrm{g}$ and $65.3 \mathrm{mg} / \mathrm{g}$ in the content of TOC and $2.4 \mathrm{mg} / \mathrm{g}$ and $2.3 \mathrm{mg} / \mathrm{g}$ in that of TN, respectively. Four days later after the start, the organic matter content of the fecal pellets increased to $69.6 \mathrm{mg} / \mathrm{g}$ in TOC and $2.7 \mathrm{mg} / \mathrm{g}$ in TN in Containers 3A after addition of organic matter on the sediment surface, while it decreased to $60.4 \mathrm{mg} / \mathrm{g}$ in TOC and $2.0 \mathrm{mg} / \mathrm{g}$ in TN in Containers $3 \mathrm{~B}$ without addition of organic matter. The organic matter content of the sediment was $71.8 \mathrm{mg} / \mathrm{g}$ in TOC and $2.7 \mathrm{mg} / \mathrm{g}$ in TN in Containers $3 \mathrm{~A}$ and $71.1 \mathrm{mg} / \mathrm{g}$ in $\mathrm{TOC}$ and $2.7 \mathrm{mg} / \mathrm{g}$ in $\mathrm{TN}$ in Containers 3B. 
(a) Containers 3A Addition of organic matter

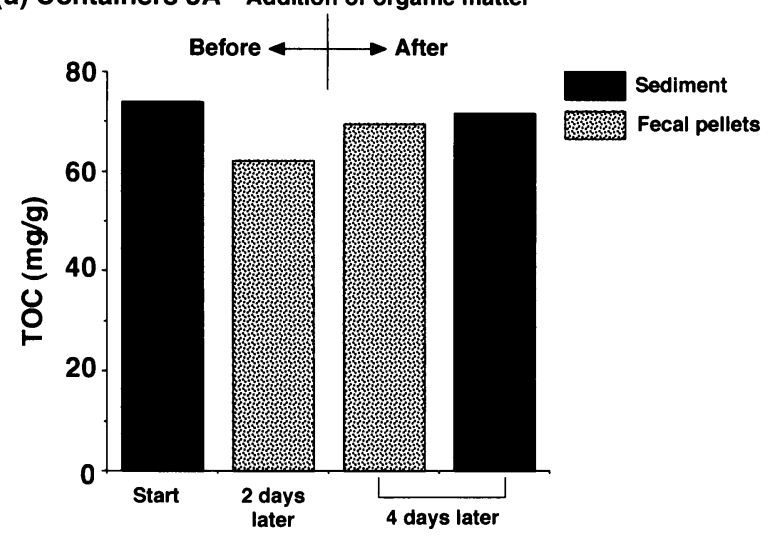

(b) Containers 3B

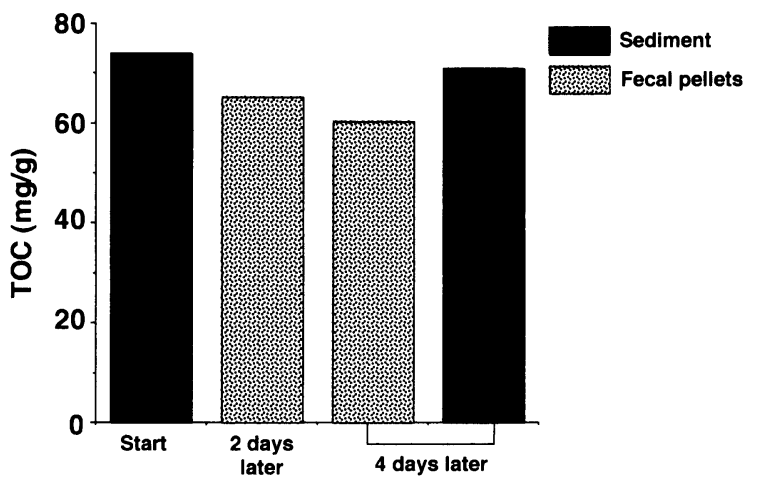

Fig. 4. Changes of TOC content of the sediment and the fecal pellets of the worms in (a) Containers $3 \mathrm{~A}$ and (b) Containers $3 \mathrm{~B}$ in Experiment 3. The data are mean of duplicates.

Thus, the organic matter content of the bulk of the sediment in both of Containers $3 \mathrm{~A}$ and $3 \mathrm{~B}$ did not change or only slightly decreased throughout the period of the experiment, while that of the fecal pellets of the worms markedly increased in Containers $3 \mathrm{~A}$ after addition of the organic matter and decreased in Containers 3B without addition of organic matter throughout the period of the experiments. Although we did not confirm statistical significance in these changes of the organic matter content of these experiments due to shortage of replicates, these facts indicate that the worms feed on the sediment selectively, and are able to utilize the organic matter put on the sediment surface selectively.

\section{Experiment 4: Selective feeding of the surface sedi- ment}

Fig. 6 shows the daily fluctuations of the amount of fecal pellets excreted by 10 individuals of Capitella sp. I in Containers $4 \mathrm{~A}$ and $4 \mathrm{~B}$. In the first three days, the mean amount of fecal pellets in both containers fluctuated between 0.008 and $0.024 \mathrm{~g} /$ day. The total amount of fecal (a) Containers 3A Addition of organic matter

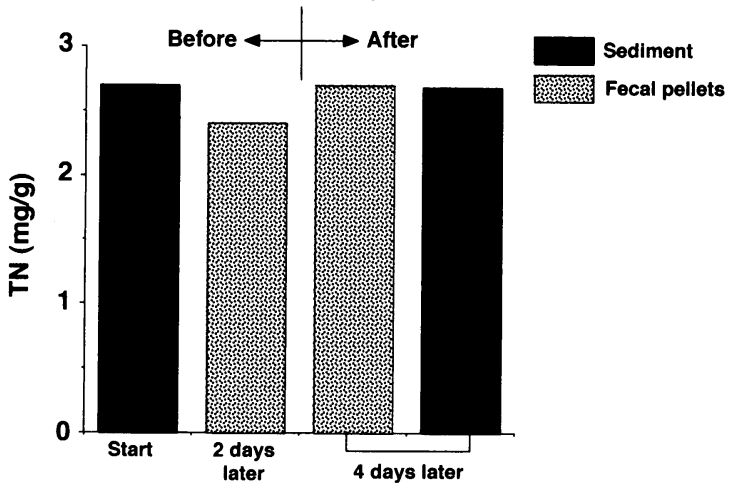

(b) Containers 3B

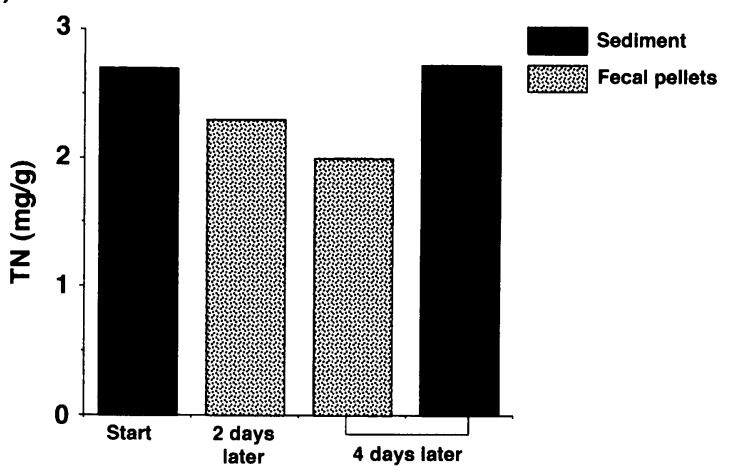

Fig. 5. Changes of TN content of the sediment and the fecal pellets of the worms in (a) Containers $3 \mathrm{~A}$ and (b) Containers 3B in Experiment 3. The data are mean of duplicates.

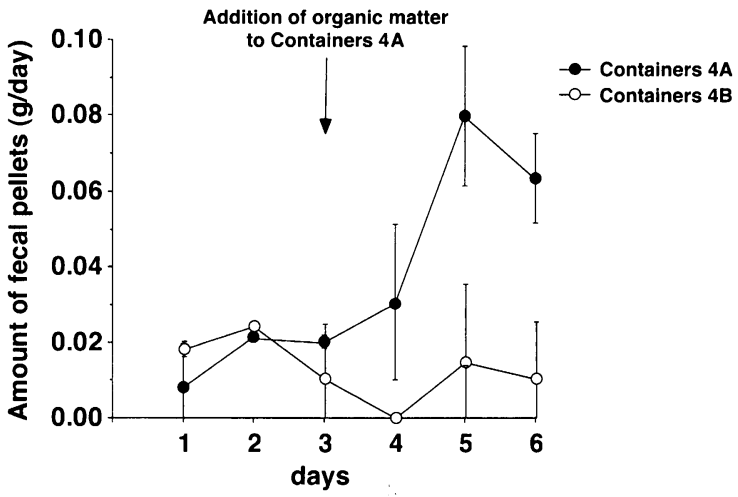

Fig. 6. Daily fluctuations of the amount of fecal pellets excreted by 10 individuals of Capitella in Containers 4A and 4B. Bars indicate standard deviation from the mean $(n=5)$.

pellets in this period was $0.049 \mathrm{~g}$ in Containers $4 \mathrm{~A}$ and $0.053 \mathrm{~g}$ in Containers 4B. In Containers 4A, the mean amount of fecal pellets increased, following the addition of organic matter on the sediment surface, and reached $0.08 \mathrm{~g} /$ day five days after the start. The total amount of fecal pellets in the latter three days was $0.174 \mathrm{~g}$, which was approximately 3.3 times larger than that in the first three days. In Containers 4B without addition of organic 


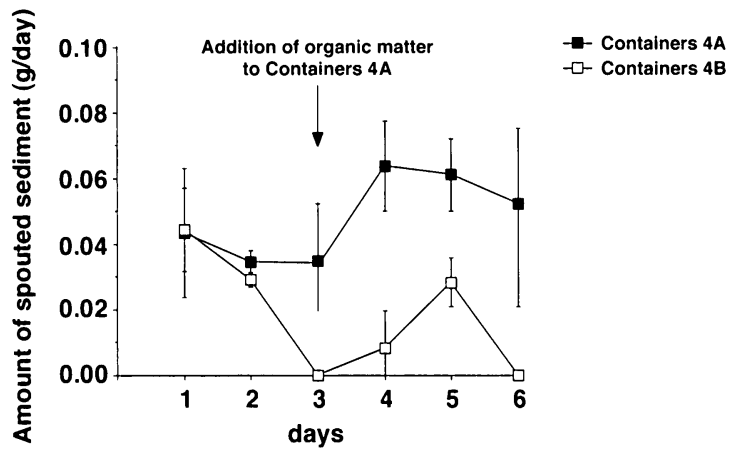

Fig. 7. Daily fluctuations of the amount of the sediment spouted from the subsurface layers due to the burrowing activities of 10 individuals of Capitella in Containers $4 \mathrm{~A}$ and $4 \mathrm{~B}$ in Experiment 4. Bars indicate standard deviation from the mean $(n=5)$.

matter, the mean amount of fecal pellets in the latter three days remained at similar levels to the first three days, 0 to $0.028 \mathrm{~g} /$ day. Thus, addition of organic matter on the sediment surface significantly stimulated the feeding activities of the worms.

Fig. 7 shows the daily fluctuations of the amount of sediment spouted from the subsurface layers due to the burrowing activities of 10 individuals of Capitella in Containers $4 \mathrm{~A}$ and $4 \mathrm{~B}$. In Containers 4A, the mean amount of spouted sediment fluctuated between 0.035 and $0.044 \mathrm{~g} / \mathrm{day}$ in the first three days, and increased to 0.52 to $0.63 \mathrm{~g} / \mathrm{day}$ in the latter three days, following the addition of organic matter on the sediment surface. In Containers $4 \mathrm{~B}$ without addition of the organic matter, the mean amount of spouted sediment fluctuated between 0 and $0.43 \mathrm{~g} / \mathrm{day}$ throughout the period of the experiment. These facts indicate that the addition of the organic matter on the sediment surface also stimulated the burrowing activities of the worms in the sediment.

Fig. 8 shows the daily changes of the number of the dark gray-and white-colored fecal pellets excreted by ten individuals of Capitella in the sediment in Containers 4A. Very few white-colored fecal pellets were collected in the first three days in the containers. From four days after the start, when we added organic matter on the sediment surface, the number of both dark gray- and whitecolored fecal pellets significantly increased to that of one day and two days after the start of the experiment $(p<0.05$, Wilcoxon signed-ranks test). Six days after the start, 289 dark gray-colored fecal pellets and 75 whitecolored fecal pellets were excreted. Approximately $21 \%$ of the fecal pellets were made up of white-colored ones. The presence of these white colored-fecal pellets indicated that the worms fed on the sediment in the whitecolored thin surface layer.

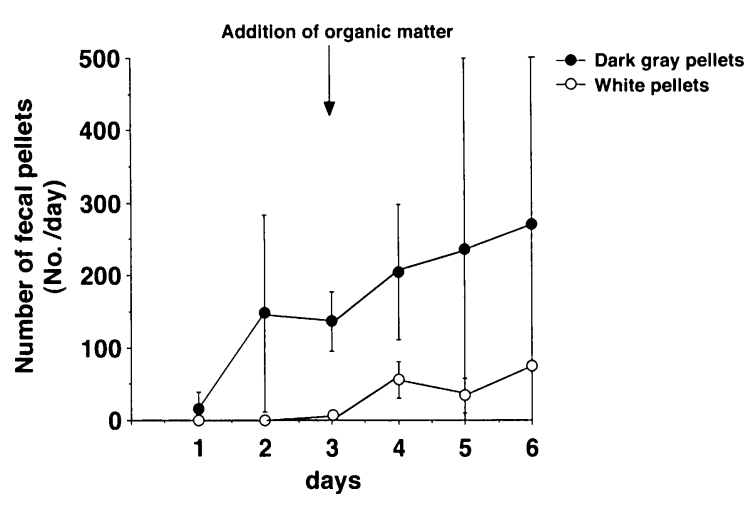

Fig. 8. Daily changes of the number of the dark gray- and white-colored fecal pellets excreted by ten individuals of Capitella in the sediment in Containers $4 \mathrm{~A}$ and $4 \mathrm{~B}$ in Experiment 4. Bars indicate standard deviation from the mean $(n=5)$.

The results of Experiment 4 indicate that the addition of organic matter on the surface sediment stimulated the feeding and burrowing activities of the worms occurring in the sediment, and that the worms were able to feed on the organic-rich surface sediment selectively.

\section{DISCUSSION}

The population dynamics of Capitella species are characterized by early recolonization and rapid population growth, which are realized by short life cycle and yearround reproduction as a population, etc. (Grassle \& Grassle 1974; Tsutsumi \& Kikuchi 1984; Tsutsumi 1987, 1990). These life history characteristics are highly adaptable to unpredictable environment (Pianka 1970; Stearns 1976; Begon \& Motimer 1981). The establishment of dense patches follows the promotion of decomposition of organic matter and oxidation of the organically enriched sediment (Chareonpanich et al. 1983, 1984; Tsutsumi et al. 2002, 2005).

The results of the experiments in this study (Fig. 3 to Fig. 8) suggest the presence of mechanisms that allow this species to quickly exploit the available organic matter in the sediment for its rapid population growth. The excretion of both of black-colored and white-colored fecal pellets by the worms in the Experiment 1 and 4 indicate that the worms feed not only at the subsurface but also at the surface sediment (Fig. 2, Fig. 8). The addition of organic matter on the sediment stimulated feeding and burrowing activities of the worms (Fig. 6 to Fig. 8). The increase of organic matter of the fecal pellets of the worms after addition of organic matter on the sediment indicates selective feeding of organic-rich particles in the sediment (Fig. 4 and Fig. 5). 
Wu et al. (2003) and Wada et al. (in press) demonstrated in the sediment microcosm experiments with Capitella sp. I that the bacterial activities were highly activated in the subsurface sediment around the burrows of the worms and the surface layer of the sediment, suggesting "bacterial gardening" (cf. Hylleberg, 1975) by the worms. It is very likely that the worms feed on the bacteria-rich subsurface sediment in their burrows and also bacteria-rich particles deposited on the sediment surface. Such feeding behaviors may enable this species to exploit the available organic matter very efficiently.

Even a single individual of Capitella sp. I tends to make many burrows, spouting the subsurface sediment on the sediment surface (Fig. 2). Therefore, the sediment inside the structure has numerous burrows like a wasp net when the dense patches are established. The overlying DO-rich water just above the sediment enters into the sediment when the burrows are made by the worms, and bacteria increase on the inner wall of the burrows $(\mathrm{Wu}$ et al. 2003; Wada et al. in press). Kunihiro et al. (2005) reported a marked increase of aerobic bacteria in organically enriched sediment below fish farms during the winter, when Capitella sp. I established extremely high density patches with over 300,000 ind. $/ \mathrm{m}^{2}$. Thus, the construction of many burrows in the sediment by the dense patches of the worms should promote the oxidation of the sediment and provide DO-rich environment that is a suitable site for increase of aerobic bacteria in the sediment. Actually, Tsutsumi et al. (2005) reported that marked decrease of reduced sulfides, AVS (Acid Volatile Sulfide), and organic matter content of the sediment occurred in the organically enriched sediment just below a net pen of a fish farm when dense patches of Capitella with over 100,000 indi. $/ \mathrm{m}^{2}$ were established below the net pen by causing a rapid population growth with addition of a mass-cultured seed colonies of the worms in the organically enriched sediment.

The worms fed and spouted the black-colored subsurface sediment with reduced conditions on the sediment surface (Fig. 2). The excreted fecal pellets and spouted sediment on the sediment surface are exposed to DO-rich overlying water and oxidized. Here, we assume a Capitella patch that includes 30,000 individuals of adult worms with $1 \mathrm{~mm}$ of maximum width of thoracic segments per one square meter and the worms feed only subsurface sediment. According to the equations between the body size of the worm and the amount of fecal pellets and spouted sediment as shown in Fig. 3, the Capitella patch excretes $45 \mathrm{~g}$ in dry weight (DW) of the subsurface sediment as fecal pellets on the sediment surface and spouted $117 \mathrm{gDW}$ of the subsurface sediment on the sedi- ment surface per square meter per day. In total, this patch is able to rework $162 \mathrm{gDW}$ of the subsurface sediment on the sediment surface per day. One square meter of the subsurface sediment with $2 \mathrm{~cm}$ in thickness, $75 \%$ of water content and 1.7 of specific gravity should be reworked on the sediment surface within 52.5 days. The Capitella patch that we assumed in this calculation is equivalent to the population with approximately $93 \mathrm{~g}$ in wet weight per square meter $\left(\mathrm{gWW} / \mathrm{m}^{2}\right)$, according to the equations between the body size and biomass of the worm (Tsutsumi et al. 2005). It is a realistic population size in the organically enriched sediment below fish farms during the winter (cf. Tsutsumi et al. 2005). Reworking activities of Capitella sp. I possess ample potential to promote the oxidation of organically enriched sediment that tends to exist in highly reduced conditions.

Acknowledgments. We would like to express our thanks to Mr. Richard Lavin for his critical reading of the manuscript. This study was supported by the Research and Development Program for New Bio-industry Initiatives.

\section{REFERENCES}

Begon M. and M. Motimer 1981. Population Ecology. Blackwell Scientific Publications, London, 200 pp.

Chareonpanich, C., S. Montani, H. Tsutsumi and S. Matsuoka 1993. Modification of chemical characteristics of organically enriched sediment by Capitella sp. I. Marine Pollution Bulletin, 26: 375-379.

Chareonpanich, C., H. Tsutsumi and S. Montani 1994. Efficiency of the decomposition of organic matter, loaded on the sediment, as a result of the biological activity of Capitella sp. I. Marine Pollution Bulletin, 28: 314-318.

Diaz, R. J. and R. Rosenberg 1995. Marine benthic hypoxia: A review of its ecological effects and the behavioural responses of benthic macrofauna. Oceanography and Marine Biology: an Annual Review, 33: 245-303.

Fauchald, K. and P. Jumars 1979. The diet of worms: a study of polychaete feeding guilds. Oceanography and Marine Biology: an Annual Review, 17: 193-284.

Forbes, T. L. and G. R. Lopez 1990. The effect of food concentration, body size, and environmental oxygen tension on the deposit-feeding polychaete, Capitella species I. Limnology and Oceanography, 35: 1515-1544.

Grassle, J. F. and J. P. Grassle 1974. Opportunistic life histories and genetic systems in marine benthic polychaetes. Journal of Marine Research, 32: 253-284.

Grassle, J. P. and J. F. Grassle 1976. Sibling species in the marine pollution indicator Capitella (Polychacta). Science, 192: 567-569.

Hylleberg, J. 1975. Selective feeding by Abarenicola pacifica 
with notes on Abarenicola vagabunda and a concept of gardening in lugworms. Ophelia, 14: 113-137.

Jumars, P. A. and K. Fauchald 1977. Between-community contrasts in successful polychaetes feeding strategies. In, Ecology of Marine Benthos, Coull, B. C. (ed.), University of South Carolina Press, Columbia, South Carolina, pp. 1-20.

Kunihiro, T., T. Miyazaki, K. Kinishita, A. Satou, A. Inoue, D. Hama, K. Ohwada and H. Tsutsumi (2005) Microbial community dynamics in organically enriched sediment below fish net pen culture with artificially cultured colonies of the polychaete Capitella sp. I. Bulletin of the Society of Sea Water Science, Japan, 59: 343-353.

Pearson, T. H. and R. Rosenberg 1976. A comparative study of the effects on the marine environment of wastes from cellulose industries in Scotland and Sweden. Ambio, 5: 77-79.

Pearson, T. H. and R. Rosenberg 1978. Macrobenthic succession in relation to organic enrichment and pollution of the marine environment. Oceanography and Marine Biology: an Annual Review, 16: 229-311.

Pianka, E. R. 1970. On r- and K-selection. American Naturalist, 104: 592-597.

Reish, D. J. 1971. Effect of pollution abatement in Los Angeles Harbours. Marine Pollution Bulletin, 2: 71-74.

Reish, D. J. 1974. The establishment of laboratory colonies of polychactous annelids. Thalassia Jugoslavica, 10: 181-195.

Reish, D. J. 1979. Bristle worms (Annelida: Polychaeta) In, Pollution Ecology of Estuarine Invertebrates, Hart. C. W. and S. H. Füller (eds.), Academic Press, New York, pp. 78-125.

Rosenberg, R. 1971. Recovery of the littoral fauna in Saltkälefjord subsequent to discontinued operations of a sulphite pulp mill. Thalassia Jugoslavica, 7: 341-351.

Rosenberg, R. 1973. Succession in benthic macrofauna in a Swedish fjord subsequent to the closure of a sulphite pulp mill. Oikos, 24: 244-258.

Rosenberg, R. 1976. Benthic faunal dynamics during succession following pollution abatement in a Swedish estuary. Oikos, 27: 414-427.

Stcarns, S. C. 1976. Life history tactics: a review of the ideas. Quarterly Review of Biology, 51: 3-47.

Tsutsumi, H. 1987. Population dynamics of Capitella capitata (Polychacta; Capitellidae) in an organically polluted cove.
Marine Ecology Progress Series, 36: 139-149.

Tsutsumi, H. 1990. Population persistence of Capitella sp. (Polychaeta; Capitellidae) on a mud flat subject to environmental disturbance by organic enrichment. Marine Ecology Progress Series, 63: 147-156.

Tsutsumi, H. and T. Kikuchi 1983. Benthic ecology of a small cove with seasonal oxygen depletion caused by organic pollution. Publications from the Amakusa Marine Biological Laboratory, Kyusyu University, 7: 17-40.

Tsutsumi, H. and T. Kikuchi 1984. Study of the life history of Capitella capitata (Polychaeta: Capitellidae) in Amakusa South Japan including a comparison with other geographical regions. Marine Biology, 80: 315-321.

Tsutsumi, H., T. Kikuchi, M. Tanaka, T. Higashi, K. Imasaka and M. Miyazaki 1991. Benthic faunal succession in a cave organically polluted by fish farming. Marine Pollution Bulletin, 23: 233-238.

Tsutsumi, H. and S. Montani 1993. Utilization of biological activities of capitellid polychaete for treatment of (Hedoro) (organically enriched sediment) deposited on the marine bottom just below net pen culture. Nippon Suisan Gakkaishi, 59: 1343-1347.

Tsutsumi, H., S. Montani and H. Kobe 2002. Bioremediation of organic matter loaded on the sediment in outdoor pools with a polychaete, Capitella sp. 1. Fisheries Science, 68: 613-616.

Tsutsumi, H., K. Kinoshita, S. Srithongouthai, A. Sato, S. Nagata, A. Inoue, M. Yoshioka, K. Ohwada and D. Hama 2005. Treatment of the organically enriched sediment below the fish farm with the biological activities of artificially masscultured colonies of a small deposit feeding polychaete, Capitella sp. I. Benthos Research, 60: 25-38.

Wada, M., S.-S. Wu, K. Kogure and H. Tsutsumi 2005. Short-terrm imapct of biological activities of a burrowing polychaete, Capitella sp. I, on bacterial abundance and the chemical characteristics in organically enriched sediment. Benthos Research, 60: 59-66.

$\mathrm{Wu}, \mathrm{S}$. S., H. Tsutsumi, K. K.-Tsukamoto, K. Kogure, K. Ohwada and M. Wada 2003. Visualization of the respiring bacteria in sediments inhabited by Capitella sp. 1. Fisheries Science, 69: 170-175. 